chapters are more or less self-contained, and cover excitation-contraction coupling mechanisms in a variety of vertebrate and invertebrate muscle types. There is some repetition, but this is no bad thing as most readers are likely to refer to a section at a time. The writing is lucid and most of the figures have been redrawn from the literature in a clear, consistent format. Controversies are generally dealt with by presenting both sides of the argument, without forcing premature conclusions.

Nevertheless, the various topics are held together with the author's own views, which the reader may or may not share. Thus, in a comparison of actin- and myosin-linked regulation, Rüegg considers that the former is more efficient because there is "a built-in guarantee that crossbridges do not hydrolyse ATP unless they are attached to actin", yet it is known that skeletal myosin alone hydrolyses ATP in vitro at a suspiciously high rate compared with a relaxed muscle. Some additional way of modulating the myosin ATPase may therefore be implicated.

Clive R. Bagshaw is a Lecturer in the Department of Biochemistry, University of Leicester, Leicester LEI 7RH, UK.

\section{All about leeches}

\section{Ronald W. Davies}

Leech Biology and Behaviour. By Roy T Sawyer. Oxford University Press:1986. $P$ p. 1,065 in three volumes. Vol. I $£ 47.50$, $\$ 85$; Vol. II $£ 42.50, \$ 85$; Vol. III £25, \$50.

Perhaps the question that almost all invertebrate zoologists would ask about books of the type written by Sawyer is "How do they compare to Libbie Hyman's volumes on the invertebrates?". The short answer is in many respects very well, but in other respects poorly.

The three volumes - Anatomy, Physiology, and Behaviour; Feeding Biology, Ecology, and Systematics; and Bibliography - cover almost all aspects of the subject matter implied by their titles, but the emphasis is upon the use of leeches in modern medicine and particularly the numerous chemicals of pharmacological use produced by leeches. Each topic is covered extensively and as a source of information the books are excellent. If, however, the reader is looking for an holistic approach fitting leeches into a more general framework, there are disappointments. This particularly applies to the ecological section, which has little interpretative content and fails to establish substantive links with mainline ecology.

Thus, like Hyman, if information is required Sawyer will generally provide it. But, unlike Hyman, there is no balanced analysis of possible phylogenetic development. Only an enthusiastic leech researcher would seriously contemplate reading these books from start to finish, but by beginning with a very personal and idiosyncratic account of the phylogenetic affinities of the leeches Sawyer will probably deter all but the most dedicated. My greatest fear is that these introductory chapters may well not only put off the casual reader but will potentially misinform or bias the unwary. For example, Sawyer suggests that certain traits reflect a monophyletic link between the Clitellata and the Uniramea, with the Polychaeta having a separate and distinct origin. Alternative views are largely ignored or barely mentioned. The dogmatic adherence to this phylogenetic perspective pervades almost every chapter and detracts from an otherwise excellent work of scholarship. Similarly, the inclusion of the Acanthobdellida and Branchiobdella within the leeches (Hirudinea) deserves more discussion, and alternative phylogenetic pathways should have at least been mentioned.

The sections on systematics, evolution and zoogeography will be extremely useful to leech researchers throughout the world, although it is a pity that Sawyer does not fully explain the taxonomic changes he has instituted. Most leech researchers are well acquainted with the publications of Soos and Richardson on leech genera of the world (published in Acta Zoologica Academiae Scientiarum Hungaricae). However, many of the genera, especially in the Hirudinidae, so carefully defined by these workers have been eliminated largely without explanation. Inclusion of this information would have undoubtedly increased the value of Sawyer's books.

The separation of the chapter on behaviour in Vol. I from those on feeding biology and ecology in Vol. II is difficult to understand, as is the separation into different volumes of phylogeny and systematics. With a common index for Vols I and II and the bibliography in Vol. III, most readers will be required to juggle two if not three volumes coincidentally. Undoubtedly space was saved as a result, but at the cost of seriously inconveniencing the user.

The books are well written and illustrated, and despite (or perhaps because of) Sawyer's personal biases on phylogeny I found them enjoyable and stimulating. The author must be congratulated on a monumental achievement, which will be invaluable to dedicated leech researchers and a must for their laboratories and every university library.

Ronald $W$. Davies is a Professor in the Department of Biology, University of Calgary, Calgary, Alberta, Canada T2N IN4.

\section{Malevolent moulds on record}

\author{
Maurice O. Moss
}

Fusarium Species: Their Biology and Toxicology. By Abraham Z. Joffe. Wiley: 1986. Pp.588. \$74.95, £71.75.

Ir WAS just six years ago that a speech made in West Berlin by US Secretary of State Alexander Haig threw the mould genus Fusarium into the spotlight of the news media. The speech linked the phenomenon of 'yellow rain' in South-East Asia with the production and use of the toxic mould metabolites known as trichothecenes as agents of chemical warfare. Although 'yellow rain' is probably the pollen-laden faeces of bees, and the truth about the use of chemical weapons in South-East Asia is distorted by the murky clouds of superpower politics, the importance of Fusarium in natural cases of poisoning of man and domesticated animals is well recognized.

Severe outbreaks of illness associated with the consumption of cereals contaminated with species of Fusarium and other moulds occurred in parts of the Soviet Union during the first half of this century. This illness, known as alimentary toxic aleukia (ATA), is associated with a complex pattern of debilitating disorders which starts with inflammation of the mouth and throat and is followed by damage to the mucosal membrane systems of the intestine and associated vomiting and diarrhoea. With increased consumption of toxic cereals, damage to the bone marrow occurs followed by a complex anaemia. The trichothecenes are now considered to be responsible for ATA. Like several other mycotoxins they are immunosuppressive, so the body's defences against bacterial and viral infections are reduced; indeed, many deaths during outbreaks of ATA were put down to pulmonary and other infections.

During a major Russian outbreak of ATA in the 1940s, Abraham Joffe was Director of the Mycology Laboratory of the Institute of Epidemiology and Microbiology in Orenburg. He was closely involved in investigations of the aetiology of the disease and continued to specialize in the study of toxigenic fusaria as head of the Laboratory of Mycology and Mycotoxicology at the Hebrew University of Jerusalem. Fusarium is only one of a number of mould genera which are known to produce toxic metabolites (zearalenone, butenolide and moniliformin, for example, as well as the trichothecenes) and there is now a considerable body of literature on the mycotoxigenic fungi, mycotoxins and mycotoxicoses. Professor Joffe has made continuous and notable contribu- 